\title{
PERCEPTION AND REFLECTION
}

\author{
Anil Gomes \\ Trinity College, University of Oxford \\ Forthcoming, Philosophical Perspectives [accepted 2017]
}

\begin{abstract}
What method should we use to determine the nature of perceptual experience? My focus here is the Kantian thought that transcendental arguments can be used to determine the nature of perceptual experience. I set out a dilemma for the use of transcendental arguments in the philosophy of perception, one which turns on a comparison of the transcendental method with the first-personal method of early analytic philosophy, and with the empirical methods of much contemporary philosophy of mind. The transcendental method can avoid this dilemma only if it commits to our possessing a capacity for imaginative reflection, one which is capable of identifying certain formal properties of experience. This result indicates some of the commitments which must be made if transcendental arguments are to be used in the philosophy of perception, and it has implications for those views that take the philosophy of perception to be autonomous of the empirical science of perception.
\end{abstract}

\section{Introduction}

Questions about perception arise across the academy: philosophers, psychologists, neuroscientists, and others are interested in the nature of perceptual experience and its role in our cognitive life. And it is a salient fact to anyone who is interested in these questions that there is disagreement both across and within these disciplines as to the nature of perceptual experience. In some cases, this is the kind of disagreement which one would expect in any healthy body of research. But in some cases it seems to betray a deeper disagreement about the methods appropriate for studying the nature of perceptual experience. 
What method should we use to determine the nature of perceptual experience? Twentieth-century philosophy saw a variety of answers to the question, but one answer which gained some popularity in the latter half of the twentieth century was the claim that we can use transcendental arguments to determine the nature of perceptual experience. In very broad terms, we can think of a transcendental argument as one which undertakes to identify necessary conditions on a certain sort of activity or state where, as Quassim Cassam puts it ' $[\mathrm{t}]$ he necessary conditions... are non-empirical or a priori conditions rather than causally necessary conditions' (Cassam, 2007 , p. 52). In the case of our theorising about perceptual experience, the thought would be that we determine the nature of perceptual experience by showing how some fact about the nature of perception is a necessary condition on some uncontested activity or state.

Does this answer have implications for the relation between the philosophy and science of perception? Transcendental arguments seem to offer a role for philosophy in the study of perception which is autonomous, in that such theorising can be pursued independently of the science of perception (Allison, 2004, p. 12; Harrison, 1982). And this seems to reflect Kant's own conception of his methodology. Transcendental philosophy, he tells us, is such that 'absolutely no concept must enter into it that contains anything empirical' (A14/B28). The reasoning seems to be that empirical methods cannot be used to determine a priori necessary conditions, and thus that the philosophy of perception must be independent of the science of perception.

These observations raise three questions which I will pursue in this essay:

1. What are transcendental arguments, and how are they used in the philosophy of perception?

2. Can transcendental arguments be used to determine the nature of perceptual experience?

3. Do transcendental arguments support an autonomous conception of the philosophy of perception?

In answer to the second question, I'll look in detail at one prominent form of transcendental argument in the philosophy of perception and identify a dilemma for such arguments which threatens the claim that transcendental arguments offer us a distinctive methodology. And in response to this dilemma, I'll suggest that transcendental arguments in the philosophy of perception can avoid these worries if they commit to our possessing a 
capacity for imaginative reflection which is capable of supporting a transcendental investigation into the nature of perceptual experience. Such a capacity would allow transcendental arguments to determine the nature of perceptual experience, but only if our interest is confined to the identification of the formal properties of perceptual experience. The central thought is that transcendental arguments need to make some further, nontrivial assumptions if they are to be capable of determining truths about the nature of perceptual experiences.

Where does this leave us? Transcendental arguments are much less popular than they were during the heyday of Oxford analytic philosophy, and one might worry that any criticisms of such arguments are correspondingly less interesting. Still, there is value in identifying the strongest form that a transcendental argument can take, and in the final section I use the discussion to draw out some implications for autonomous approaches to the philosophy of perception. For if the arguments that I make here are along the right lines, then the transcendental method secures autonomy in the philosophy of perception only if it makes substantive commitments about the way that the first-person perspective is involved in perceptual experience. These commitments were part of early analytic thinking about the nature of perception, and the question we are left with is whether a defence of autonomy in the philosophy of perception can be mounted absent the substantive methodological commitments of our early analytic predecessors.

\section{Transcendental Arguments}

According what I will call the transcendental method, we can use transcendental arguments to discover the nature of perceptual experience. Transcendental arguments are arguments which set out to uncover the a priori or non-empirical necessary conditions on certain activities or states of affairs. In their standard form, they start with something which every party to the debate takes as uncontested. (This can differ from debate to debate.) They then identify something which is a broadly a priori necessary condition on the obtaining of the uncontested starting point. That necessary condition is typically something which one party to the debate contests. In this way, the method is meant to have dialectical force against 
one's opponents by showing that something which one's opponent disputes is a condition on something which she takes for granted. ${ }^{4}$

Transcendental arguments in twentieth-century analytic philosophy were typically world-directed: that is, they took the necessary condition in question to be a claim about how things are in the world. We can contrast these with self-directed transcendental arguments. (The terminology comes from (Cassam, 1999).) Self-directed transcendental arguments take the necessary condition to be some feature or aspect of the perceiving and knowing subject. Kant's own transcendental arguments in the first Critique are typically self-directed: we start with some supposedly uncontested claim - say, the synthetic a priori status of geometry - and we argue to a claim about the cognitive faculties of the subject - namely, that space is a pure form of intuition. Transcendental arguments in the philosophy of perception are self-directed and, in this sense, are closer in character to Kant's own arguments than many of the world-directed arguments put forward on his behalf. ${ }^{5}$

In the case of the philosophy of perception, the transcendental method has the following generic structure: it starts with some state or activity $\mathrm{T}$ which is agreed to be actual. It is then argued that perceptual experience must be a particular way if $\mathrm{T}$ is to be possible. This methodology can, in principle, be combined with a variety of starting points but transcendental arguments in the philosophy of perception typically begin with some claim about our capacity to think in a certain way. It is then argued that perception must be some particular way if we are to be capable of thinking in the specified way. Such arguments gained currency in the twentieth century through the work of P.F. Strawson, and the use of such arguments to support conclusions in the philosophy of perception remained a central part of Oxford philosophy in the twentieth century. Examples can be found in the work of Gareth Evans (1980), John McDowell (1986, 1994, 2008), Quassim Cassam (1997), John Campbell (2002b) and, of course, Strawson himself $(1959,1966)$.

\footnotetext{
${ }_{4}^{4}$ Transcendental arguments are usually traced back to Kant's Critique of Pure Reason. There was considerable interest in their structure and prospects in the 1960s and 1970s, largely prompted by the work of P.F. Strawson. See the introduction to (Stern, 1999) for a good summary of the background to these debates, and (Cassam, 1987; Harrison, 1982; Stroud, 1968) for influential discussions.

5 The distinction between world- and self-directed transcendental arguments is complicated in Kant by his transcendental idealism, since necessary conditions which look, in the first place, to be features of the cognitive subject have immediate implications for the nature of the world in virtue of the transcendental idealism. Something similar applies in the case of some self-directed arguments in the philosophy of perception, since some views about the nature of perception have immediate implications for the nature of the world.
} 
Even at this level of generality, there are deep and interesting questions about the nature of transcendental arguments which could be pursued. These include questions about the status of the necessity claim, the nature of the necessity in question, the source for that necessity, and so on. Many of these questions have been pursued illuminatingly in a variety of contexts, not least in the interpretation of Kant's own arguments. ${ }^{6}$ I'll put them to one side for now. Let us proceed as if it is reasonably clear how the methodology is supposed to work.

In schematic terms, a transcendental argument in the philosophy of perception will thus have the following structure:

1. $\mathrm{T}$ is actual.

2. It is a condition on $\mathrm{T}$ being possible that perceptual experience have feature F.

3. Perceptual experience has feature F.

There are questions about whether this form of argument is distinctive of transcendental arguments or whether it is simply a version of modus ponens. Let us bracket that issue for the moment. And note that the second step may itself be broken down into a number of distinct steps, each of which identifies a necessary condition. The end result is a claim about how perception must be if $\mathrm{T}$ is to be actual.

The dialectical power of this argument structure will depend in part on the nature of $T$. One starting point is the observation that ' $[\mathrm{w}] \mathrm{e}$ ordinarily think that the world around is independent of our minds' (Campbell in Campbell \& Cassam, 2014, p. 1). Let us say that this way of thinking about the world makes use of a conception of an objective world (Evans, 1980 , p. 76). What must the nature of perception be like if we are to possess this conception of an objective world? John Campbell calls this Berkeley's Puzzle: the puzzle of explaining 'how our concepts of mindindependent objects could have been made available by experience of them' (Campbell, 2002a, p. 128). This is the puzzle that occupies Oxford thinking about the philosophy of perception in the twentieth century and it is framed by the way in which the issues are set up in Strawson's Individuals and The Bounds of Sense. Call such arguments objectivityoriginating transcendental arguments.

${ }^{6}$ See (Cassam, 1987; Harrison, 1982; Stroud, 1968) and the papers in (Stern, 1999). 
How we should understand the notion of objectivity as it features in the conception of an objective world? There are two broad notions of objectivity: an ontological notion and a perspectival notion. According the ontological notion, something is objective when it doesn't dependent for its existence on minds and subjective otherwise. According the perspectival notion, whether or not something is objective turns on the extent to which it is tied to our point of view; things are objective to the extent that they are independent of a subject's point of view and subjective otherwise.

These notions are distinct. ${ }^{7}$ In Individuals and The Bounds of Sense, Strawson is primarily concerned with a version of the ontological notion. On Strawson's construal, something is objective iff it doesn't constitutively depend for its existence on a subject's act of awareness; and subjective otherwise. This is the way that the notion of objectivity is picked up by Evans (1980, pp. 77-78), Cassam (1997, p. 28) and Campbell (2014, pp. 28-35). A transcendental argument which takes this as its starting point must argue that it is a condition on possessing a conception of an objective world, as according to this conception of objectivity, that perceptual experience be some way. What are the prospects for such an argument?

\section{Necessary Conditions}

One question concerns the starting point for these arguments. Let us put that to one side and grant the first premise. The question to be pursued here is how we are to support the second premise. We have said that transcendental arguments aim to uncover a priori necessary conditions. One way in which necessary conditions can be known a priori is when the conditional in question is an analytic or broadly conceptual truth, in some sense of those contested terms. ${ }^{8}$ So one thought is that the conditional in a transcendental argument is to be supported by the kind of reasoning which we employ to come to know conceptual or analytic truths.

One problem here is that those who are sympathetic to the arguments of Quine (1960) and Williamson (2007, pp. 73-133) will be unconvinced that there are any such truths. A second, and more significant, problem is that those who are inclined to doubt that perceptual experience has feature $\mathrm{F}$ are likely to also doubt that it is an analytic or broadly conceptual truth that it is a condition on thinking objectively that perceptual experience has feature F. Insisting that it is part of the concept of thinking objectively that it requires perception to have feature $F$ runs the risk of begging the

\footnotetext{
${ }^{7}$ See (Gomes, 2016, pp. 947-948) for discussion.

${ }^{8}$ See (Walker, 1978, pp. 18-20) and (Bennett, 1966, pp. 41-44) for this suggestion.
} 
question against one's opponent by simply stipulating that the contested feature of perceptual experience is built into our concept of objective thought. ${ }^{9}$

A second option would be to claim that there is empirical support for the conditional. Perhaps the best account of the workings of our perceptual system make it plausible that we wouldn't be able to think objectively unless ' $[\mathrm{i}] \mathrm{t}$ is part of the nature of perceptions... that they have the representational function of representing veridically' (Burge, 2010, p. 75). This would give us a transcendental argument in the philosophy of perception, the main conditional of which is supported by empirical investigation into the nature of perceptual experiences.

There are two concerns one might have about this approach. The first is that transcendental arguments, as we have presented them, aim to identify broadly a priori or non-empirical conditions, and it is not clear whether we should think of a condition which is established by reflection on the empirical study of perception as meeting that characterisation. Say that we should not think of such a condition as broadly a priori. Does this constitute an objection to the idea that the second premise might be supported empirically? One could instead respond by asking why we should build it into the definition of a transcendental argument that the necessary conditions it deal with be broadly a priori and non-empirical. An alternative would be to hold that transcendental arguments aim to identify constitutive conditions as opposed to mere causal conditions. If we thought that constitutive conditions could only be known a priori, that might explain the move from the claim that transcendental arguments identify constitutive conditions to the claim that they identify broadly a priori conditions - but once we reject that claim, then the possibility of supporting the second premise of a transcendental argument by means of empirical investigation looks much less problematic. Of course, we will have to make plausible that the empirically-identified condition in question is genuinely constitutive but nothing as yet has been said to rule that out. ${ }^{10}$

\footnotetext{
${ }^{9}$ Strawson's arguments in The Bounds of Sense are often assumed to involve covert conceptual analysis, but the main argument in the section on objectivity and unity (1966, pp. 72-117) doesn't involve any notion of analyticity. (Compare Jonathan Bennett's use of the unobviously analytic (1966, pp. 41-44) in his reconstruction of Kant's arguments.) Nor is it clear whether and if so, to what extent, he takes the claims to be conceptual truths of some sort. See (Cassam, 2016) for discussion.

${ }^{10}$ See (Kitcher, 1990) for someone who embraces this implication and (Allison, 1996, pp.

53-66; Cassam, 2003) for criticism. Burge is clear that his interest is in constitutive
} 
A second objection turns on the claim that transcendental arguments offer us a distinctive methodology in the philosophy of perception. For one worry about this suggestion is that it threatens to collapse the distinction between the transcendental method and more general empirical reasoning in the philosophy of perception.

Consider, in this regard, Tyler Burge's recent homily on methodology in the philosophy of perception:

The psychology of perception, particularly vision, has become serious science. It has well-established results and successful application of mathematical methods. There is no good reason to doubt that it provides insight not only into the mechanics of perception, but into aspects of its nature. (Burge, 2005, p. 9; cf. Burge, 2010, pp. xiv-xviii; 2011, p. 44)

Burge takes the method for determining truths about the nature of perceptual experience to involve attention to the empirical psychology of perception. Call this the empirical method. It is a central part of Burge's writing on the nature of perception that the empirical method genuinely answers constitutive questions about the nature of perceptual states. ${ }^{11}$

According to the proposed suggestion, the key premise in the transcendental argument is one which is supported by empirical results in the psychology of perception. But if that's the case, then the transcendental method looks to collapse into the empirical method. The result is a retreat from the idea of the transcendental method as a distinctive methodology.

We have a dilemma. I've suggested that objectivity-originating transcendental arguments start with the claim that we possess a conception of an objective world, and then argue that it is a necessary condition on our possessing or being justified in using such a conception that perception

conditions, and that these can have empirical support (Burge, 2010, pp. xv-xvi; 5-11; 5760). See (B3-4) for Kant's reasons for thinking that constitutive conditions can only be identified a priori.

11 There are different forms in which one could endorse the empirical method. In its strongest form, one might think that the nature of perception can be established by the natural sciences alone in a way which makes the idea of a 'philosophy of perception' look somewhat curious and outdated, analogous perhaps to a philosophical investigation into the nature of water. Weaker versions may allow a distinctive role for philosophical reflection, whilst insisting that 'philosophical questions are continuous with the empirical sciences... [w]ork in the empirical sciences is deeply relevant to philosophical questions and our philosophical theories are constrained and guided by results in other disciplines' (Kornblith, 2002, pp. 26-27). Either way, I take the methodology to involve a commitment to the idea that 'philosophical work on [the nature of perception] is insular and irrelevant [when lacking a] genuine understanding of relevant science' (Burge, 2010, p. xvii). 
be some particular way. And I've raised a dilemma for such arguments: either we take the conditional in such arguments to be established empirically, in which case the transcendental method ceases to look like an alternative to the empirical method; or such conditionals are to be established as analytic or conceptual truths, in which case the method looks like it will fail to have dialectical force. In short: transcendental arguments look either uninteresting or inert.

\section{Transcendental Arguments and the First-Person Perspective}

Are there alternatives? So far I've been assuming that to support the claim that it is a condition on $\mathrm{T}$ being possible that perceptual experience have feature F, we either take it that it is analytically or conceptually true that it is a condition on $\mathrm{T}$ being possible that perceptual experience have feature $\mathrm{F}$ or we take it that empirical psychology establishes that it is a condition on $\mathrm{T}$ being possible that perceptual experience have feature $\mathrm{F}$. But one might think that there are ways in which we could support the conditional in (2) which don't appeal to analytic or conceptual truths, but likewise fall short of an appeal to the results of empirical psychology. Suppose that the claim about perceptual experience having feature $\mathrm{F}$ is a claim which, if true, is reflected in the phenomenal character of perceptual experience. Then one might think that claims about it being a condition on $\mathrm{T}$ being possible that perceptual experience have feature F can be supported by the kind of knowledge we have of the character of our own perceptual experience. Such knowledge isn't analytic or conceptual in any sense, but nor is it secured by results in empirical psychology. And one can understand why someone might think it 'broadly a priori' or 'nonempirical' knowledge, even if the terminology is not perfect.

One way to pursue this option is to take what I'll call the Direct Approach. According to the Direct Approach, the second premise in a transcendental argument can be supported directly by the knowledge we have of the phenomenal character of our own experience. Someone who takes this approach would commit the transcendental method to claims about the methodology of perceptual experience which were central to the development of philosophy at the start of the twentieth century, both in the analytic revolt against idealism, and in the phenomenological tradition 
which originates with Husserl's Logical Investigations. I'll focus here on the analytic strand. ${ }^{12}$

Consider the chapter on Sense Data in G.E. Moore's Some Main Problems of Philosophy, written for delivery as a series of lectures in 1910 but not published until 1953:

I wish to illustrate what I have to say about seeing by a direct practical example; because, though I dare say many of you are perfectly familiar with the sort of points I wish to raise, it is, I think, very important for every one, in these subjects, to consider carefully single concrete instances, so that there may be no mistake as to exactly what it is that is being talked about... I propose, therefore, to hold up an envelope in my hand, and to ask you all to look at it for a moment; and then to consider with me exactly what it is that happens, when you see it: what this occurrence, which we call the seeing of it, is...

[W] hat happened to each of us, when we saw that envelope? I will begin by describing part of what happened to me. I saw a patch of a particular whitish colour, having a certain size, and a certain shape, a shape with rather sharp angles or corners and bounded by fairly straight lines. These things: this patch of a whitish colour, and its size and shape I did actually see. And I propose to call these things, the colour and size and shape, sense-data things given or presented by the senses-given, in this case, by my sense of sight. (Moore, 1953, pp. 29-30)

In this passage, Moore instructs his audience to follow a certain method. Similar instructions can be found throughout Moore's writings on the nature of perception (Moore, 1925, pp. 54-55). And the supposed result of following this method is the identification of a truth about the nature of perceptual experience, namely that it involves a relation to sense-data.

How should we characterise the method that Moore uses here? The most important feature is that it involves reflecting on the character of one's own perceptual experience and thus can only be undertaken first-personally; one cannot delegate the task to a graduate student in the manner of a grand Professor on the continent. (Go, pick out that sense-datum that I might examine it!) Moore holds that when we reflect first-personally on

\footnotetext{
${ }^{12}$ For discussion of the phenomenological tradition in the philosophy of perception and its commitment to a methodology involving the first-person perspective on perception, see (Husserl 1917, reprinted in 2002), and (Siewert, 2015; Thomasson, 2005) for discussion. Cf. (Thomasson, 2007a) for a comparison of Husserl's methodology with that of ordinary language philosophy.
} 
our perceptual experience, it is transparent to us that perceptual experience is or involves a relation to sense-data. ${ }^{13}$

Let us call Moore's approach the first-person method. It is central to this method that the first-person perspective can reveal truths about the nature of perceptual experience. Similar claims are held by H.H. Price (1932, p. 3 ) and perhaps by the Oxford Realists (Cook Wilson, 1926, pp. 780-782), at least until Prichard's (1938) recantation. Each of these early analytic philosophers assumes that we find out certain truths about the nature of perceptual experience simply by reflecting on the character of our perceptual experience as presented to the first-person perspective.

The Direct Approach holds that the conditional in a transcendental argument can be established by reflection on the phenomenal character of perceptual experience. But why should we think that reflection on the character of experience, as presented first-personally, reveals truths about the nature of perceptual experience? I have characterised early analytic philosophy as endorsing the first-person method. But contemporaneous with Moore's introduction of the first-person method was a corresponding scepticism about whether such a method could reveal the existence of sense-data or, perhaps more strongly, whether such a method could reveal anything about the nature of perceptual experience. Some of this comes out in George Dawes Hicks's discussion with Moore at the 1917 session of the Aristotelian Society, but it is most clear in G.A. Paul's contribution to the 1936 session, 'Is there a Problem about Sense-Data?'. The problem of sense-data for Paul is the problem of ascertaining how there can be substantial truths about the nature of perceptual experience. And his scepticism is a scepticism about the idea that the first-person perspective can reveal anything substantive about the nature of perceptual experience.

These concerns can be used as an objection to the Direct Approach. For how can the knowledge we have of the phenomenal character of experience can establish a claim of the form that it is a condition on $\mathrm{T}$ that perceptual experience have feature F? Reflection on the phenomenal character of experience looks like it could establish that perceptual experience has feature F, at least for cases in which feature $F$ is reflected in the

\footnotetext{
${ }^{13}$ Note that, as Moore introduces it, the term 'sense-datum' is neutral on the ontological nature of sense-data, so it is not that this first-personal methodology settles all the philosophical questions about the nature of perceptual experience that one might be interested in. Indeed, Moore's writings on the philosophy of perception can be seen as a somewhat painstaking and laborious investigation into the immediate implications of the supposed fact that perceptual experience is a relation to sense-data. See (Snowdon, 2007) for evidence and discussion.
} 
phenomenal character of perceptual experience. But how could it establish the modally stronger claim? Note that the problem is not just, as Kant puts it, that ' $[\mathrm{e}]$ xperience teaches us, to be sure, that something is constituted thus and so, but not that it could not be otherwise' (B3), since one might allow that experience can teach us how things must be whilst balking at the suggestion that it could teach us that it is a condition on $\mathrm{T}$ that perceptual experience be F. (In this sense, the objection is stronger than the one that Paul raises against Moore.) The second premise simply looks far too rich to be supported by reflection on the character of perceptual experience.

A second concern is also pertinent, and parallels a concern raised above: that the Direct Approach threatens to make the transcendental method non-distinctive. According to the proposed suggestion, reflection on the phenomenal character of our perceptual experience can establish a claim of the form that it is a condition on $\mathrm{T}$ that perceptual experience have feature F. And this looks equivalent to thinking that the first-person perspective on perception can identify truths about the nature of perception, as claimed by the first-person method. Transcendental arguments no longer look like a competitor to the methodology of early analytic philosophy.

\section{Transcendental Arguments and Reflection}

What are our options? The suggestion we're pursuing is that the dilemma set out above might be avoided when the claim about perceptual experience in question is one which is reflected in the phenomenal character of perceptual experience. What does it mean to say that a feature of perceptual experience is reflected in the phenomenal character of perceptual experience? I'll understand this claim to entail the claims that perceptual experience has feature $\mathrm{F}$ and that it seems to us that perceptual experience has feature F. When these conditions hold, I'll say that perceptual experience manifestly has feature F. We can now amend our transcendental argument as follows:

R1. T is actual.

R2.It is a condition on $\mathrm{T}$ being possible that perceptual experience manifestly have feature $F$.

R3. Perceptual experience has feature F.

Since perceptual experience manifestly having feature $\mathrm{F}$ entails that it has feature $\mathrm{F}$, the conclusion follows from the premises. 
The issue under consideration is whether the second premise in this revised argument can be supported by the kind of knowledge we have of the phenomenal character of our own perceptual experience. Such knowledge isn't analytic, but nor is it supported by scientific investigation. I've suggested that it is implausible to think that the second premise could be supported directly by the knowledge we have of the phenomenal character of our own perceptual experience. But perhaps reflection on the phenomenal character of perceptual experience isn't meant to support (R2) directly. As Strawson puts it in the opening sentences of The Bounds of Sense, 'It is possible to imagine kinds of world very different from the world as we know it. It is possible to describe types of experience very different from the experience we actually have... [But] There are limits to what we can conceive of, or make intelligible to ourselves, as a possible general structure of experience' (1966, p. 15). The suggestion here is that we support claims of the form of (2) and (R2) by arguing for their contrapositive: that if perceptual experience didn't have feature F, or didn't manifestly have feature $\mathrm{F}$, then $\mathrm{T}$ would not be possible.

This pushes us to the question of how we argue for the contrapositive of (2) and (R2). One option is to hold that the contrapositives of (2) and (R2) are conceptual or analytic truths, but this would seem to be open to the same concerns that befell the claim that (2) and (R2) are themselves conceptual or analytic truths. An alternative is to hold that the contrapositive of (R2) specifically can be supported by reflection on the kinds of things which would be possible if perceptual experience didn't manifestly have feature F. This kind of reflection would involve consideration of counterfactual possibilities, but instead of confining itself to analytic connections between concepts it may draw on the knowledge we have of the phenomenal character of our own perceptual experiences.

Let us call such a process of counterfactual speculation imaginative reflection, with reference to Kant's definition of reflection as 'the state of mind in which we first prepare ourselves to find out the subjective conditions under which we can arrive at concepts' (A260/B316; cf. Locke on reflection (EHU 1975 [1689] II.1.4)). Imaginative reflection draws on the knowledge we possess of the phenomenal character of our perceptual experience and exploits various of our imaginative and reflective capacities to provide us with support for modal claims about whether certain nonactual types of perceptual experience could support various forms of thought. The procedure operates as follows: imagine how things would seem to you if perceptual experience were not manifestly F. Now reflect on the kinds of things that you would be able to do in that situation. 
Capacities you lack in that situation can be taken as ones for which perceptual experience possessing the feature $\mathrm{F}$ is a necessary condition. ${ }^{14}$

Even at this schematic level of description, the practice of imaginative reflection can be identified in many of the twentieth-century transcendental arguments in the philosophy of perception. Strawson asks us to imagine a sense-datum experience - one on which there was no difference between the awareness of an object and its existence - and concludes that such experience wouldn't make room for the thought of experience itself (1966, pp. 97-112). Gareth Evans imagines a world of purely sensory properties and asks whether we could extract the idea of an objective property from this world (1980, p. 98f.). And John Campbell asks whether our conception of a mind-independent world could be made available by the experience of a conscious image, before concluding that it could not (2002a, pp. 134-135). In each case, support is provided for claims of the form of (R2) by imaginative reflection on what we would be able to do or how we would be able to think were perception to lack the phenomenal feature in question.

One might even trace this methodology back to the first Critique. In the first and second metaphysical expositions of the concept of space, Kant argues it is a condition on our capacity to represent sensations as outside and next to one another that we have a representation of space which is a priori (A23-25/B38-39). And he seems to do so by imaginative appeal to the kinds of things which beings without spatial representation could not do. Similar forms of reflection can be seen in the isolation argument at the start of the Aesthetic - imagine a representation of a body without impenetrability, hardness colour etc. (A20/B35); in the consideration of deviance in the appearance of cinnabar - imagine if cinnabar 'were now red, now black, now light, now heavy' (A100-1); and in the discussion of variety in appearances and its implications for the possibility of judgement - imagine a world in which there was such a great variety that not the least similarity could be detected (A653-4/B681-2). In each of these cases,

\footnotetext{
${ }^{14}$ Imaginative reflection, as I have described it here, has some parallels with Husserl's methodology of eidetic reduction, though without Husserl's limitation of the inputs into such reflection to the character of experience as described from the first-person perspective. See (Husserl 1917, reprinted in 2002), in particular his discussion of the links between imagination ('phantasy') and possibility. And cf. (Thomasson, 2007b; Zahavi, 2007) on the transcendental aspects to Husserl's methodology, and (Thomasson, 2007a) on the imaginative aspect to Husserl's methodology and its links to the methodologies of Oxford philosophy. More generally, imaginative reflection corresponds to Williamson's claim that the epistemology of metaphysical modality 'is simply a case of the epistemology of counterfactual thinking’ (Williamson, 2007, p. 178), cf. (Hill, 2006). One way to think about the process of imaginative reflection is as instantiating the account of our knowledge of modal truths defended by Williamson and Hill.
} 
reflection on counterfactual possibilities is supposed to reveal general truths about the conditions necessary for certain mental activities. It is not irrelevant that Kant emphasises the role of reflection when discussing the methodology of the first Critique (A261/B317, cf. CPJ 5:294, An $7: 134 n.){ }^{15}$

We have then a promising route out of the dilemma I posed to transcendental arguments in the philosophy of perception. To recap, the dilemma concerned the kind of support which could be provided for the conditional in the argument. If one takes the conditional to be established by empirical results in the psychology of perception, then one loses the contrast between the transcendental method and the empirical method. And if one takes it to be established by some form of conceptual analysis, then one loses the possibility of such transcendental arguments having dialectical force. To avoid these options, I've suggested that proponents of transcendental arguments can move to the revised argument (R1)-(R3), and hold that the conditional in that argument is supported by imaginative reflection on how things would be if perceptual experience didn't manifestly possess the feature in question. This is how the method is used in twentieth-century analytic philosophy. And it seems to offer the promise of an a priori transcendental argument which doesn't turn on the analysis of concepts. Here is a first conclusion: to the extent that transcendental arguments are to offer a distinctive methodology in the philosophy of perception, they should make use of the notion of imaginative reflection.

\section{Transcendental Arguments and Silence}

But trouble lurks. It is a basic logical point that distinctions which are exhaustive and exclusive may fail to be so once embedded in experiential operators. Everything is either made in India or not made in India. But it is not the case that everything is either experienced as being made in India, or experienced as not being made in India. Some things - most things are experienced as neither. Similarly, for any feature F, it may be true that either perceptual experience is $\mathrm{F}$ or perceptual experience is not $\mathrm{F}$, but it does not follow that everything is either experienced as being $\mathrm{F}$ or experienced as being not F. Some things, many things, may be experienced as neither. Call this the Embedding Point (Gomes, 2016, p. 948).

\footnotetext{
15 See (Westphal, 2004, pp. 12-32) and (Marshall, 2014, pp. 564-567) for discussion of the role reflection plays in Kant's arguments. There is an alternative way of reading the metaphysical expositions which places more emphasis on Kant's definition of exposition as 'the distinct (even if not complete) representation of that which belongs to a concept' (B38) but it may be that this is compatible with allowing reflection to play a role in some of the argument.
} 
If imaginative reflection on counterfactual possibilities is to establish (R2), then we need to be sure that imaginative reflection establishes the true contrapositive of (R2): that if perceptual experience didn't manifestly have feature $\mathrm{F}$, then $\mathrm{T}$ would not be possible. But there are two ways in which perceptual experience can fail to manifestly have feature F. One is when it manifestly lacks feature F. Another is when it neither manifestly possesses nor manifestly lacks feature F. The instances of imaginative reflection which I have identified in Strawson, Evans, and Campbell are all cases in which support is given for the claim that if perceptual experience manifestly lacked feature $\mathrm{F}$ then $\mathrm{T}$ would not be possible. But support for that claim falls short of establishing the contrapositive of (R2), since nothing has yet been said about whether $\mathrm{T}$ would be possible in cases in which perceptual experience neither manifestly possesses nor manifestly lacks feature F. We need a further step if the argument is to be completed.

An example will illustrate the point. Consider John Campbell's argument for a relational conception of perceptual experience:

\begin{abstract}
On the common factor view, all that experience of the object provides you with is a conscious image of the object. The existence of that conscious image is in principle independent of the existence of the external object. The existence of the image, though, is dependent on the existence of the subject who has the conscious image. So if your conception of the object was provided by your experience of the object, you would presumably end by concluding that the object would not have existed had you not existed, and that the object exists only when you are experiencing it. We cannot extract the conception of a mindindependent world from a mind-dependent image; this is the traditional problem with Locke's doctrine of abstraction. (Campbell, 2002a, pp. 134-135)
\end{abstract}

Although he would dislike the characterisation (Campbell, 2011, pp. 4547), this part of Campbell's argument can be read as a transcendental argument. We possess a conception of a mind-independent world. It is a condition on our possessing a conception of a mind-independent world that perception is a primitive relation that subjects stand in to mindindependent objects. Therefore perception is a primitive relation that subjects stand in to mind-independent objects. The main conditional in this argument is supported by the passage above: if perceptual experience involved the presentation of a conscious image of an object, then one couldn't extract the conception of a mind-independent word. And one interpretation of this passage is that we are supposed to come to know this 
conditional on the basis of imaginative reflection on the kinds of possibilities which would be open to us if perceptual experience involved the presentation of a conscious image.

Why should it be true that if perceptual experience involved the presentation of a conscious image of an object, then one couldn't extract the conception of a mind-independent world? Campbell seems to assume that the presentation of a conscious image is manifestly the presentation of a conscious image: subjects who are presented with a mind-dependent image are aware of themselves as so presented. Someone who used such an image to ground her conception of the physical world could only think of the physical world as dependent on her mind. So the presentation of a conscious image couldn't support a conception of the world as objective.

However, this argument, even if good, supports only the claim that if perception were manifestly not a relation to mind-independent objects - if, for example, it manifestly involved the presentation of a conscious image then we would not be able to extract from perceptual experience the conception of a mind-independent world. But this leaves open the possibility that we could extract the conception of a mind-independent world from perceptual experience which was neither manifestly a relation to objects nor manifestly not a relation to objects. We need to rule out this possibility if the argument is to go through. There is a gap in Campbell's argument. ${ }^{16}$

These considerations suggest that we need to be more careful in distinguishing cases in which perceptual experience is manifestly not $\mathrm{F}$ from cases in which perceptual experience is not manifestly F. The latter includes the former, but it also includes those cases in which perceptual experience is neither manifestly F nor manifestly not F. Call these cases cases of silence, since perceptual experience is, in such cases, silent on the presence or absence of F. Campbell's argument goes awry because it overlooks cases of silence, and the question the foregoing leaves us with is whether imaginative reflection on cases of silence can complete the case for the true contrapositive to (2): that if perceptual experience didn't manifestly have feature $\mathrm{F}$, then $\mathrm{T}$ would not possible. Extant transcendental arguments don't consider cases of silence - but this looks like a failing in their arguments. Here, then, is a second conclusion: extant

${ }^{16}$ Similar problems arise for the argument that Evans puts forward in 'Things Without the Mind' and for Strawson's argument in The Bounds of Sense. See (Gomes, 2016) for discussion. 
transcendental arguments in the philosophy of perception fail because they ignore cases of silence.

Can imaginative reflection be used to determine whether a certain activity would be possible in cases of silence? There are at least grounds for concern. One immediate question is whether a capacity which draws on the knowledge we have of the phenomenal character of our own mental states can be used to determine claims about how things would be if perceptual experience neither manifestly possessed nor manifestly lacked that character. Cases of silence are cases in which experience fails to take a stand on whether experience is F or not F. And one might wonder how reflection which draws on the knowledge we have of the phenomenal character of our own experiences can take a stand on whether that sort of experience could support the kind of thinking in question. At the very least, we have not yet been given any indication to think that it can. And without a way of extending imaginative reflection to cases of silence, transcendental arguments will fail.

If imaginative reflection cannot take a stance in cases of silence, does this mean that the transcendental method must be abandoned? There is one avenue left open to the proponent of transcendental arguments. The problem of silence arises because distinctions which are exhaustive may fail to remain so once embedded in experiential operators. But consider those properties which maintain their exhaustiveness when embedded in experiential operators. That is, consider those properties for which experience is never neutral: it either reports their presence or their absence. I'll call these formal properties, in the manner of Kant's distinction between the form and matter of cognition and appearances (A20/B34; A266268/B322-B324; JL 9:33). Formal properties are defined in such a way that they do not allow cases of silence. So a transcendental argument which confined itself to formal properties would not need to deal with the problem of silence. Imaginative reflection offers us a way of coming to know the conditional in a transcendental argument which confines itself to the formal properties of perceptual experience.

Formal properties can be contrasted with invariant properties. Let experience be capable of registering three values for any particular property: its presence (' 1 '), its absence (' 0 '), or neither ('-'). The formal properties are ones for which experience always reports a ' 1 ' or a ' 0 '; invariant properties are ones for which experience always reports a ' 1 '; and material properties, say, are ones for which experience can report all three values. Kant's arguments in the Transcendental Aesthetic have often been construed as 
aiming to identify the invariant properties of experience, and since cases of silence do not arise for invariant properties, it may be thought that a transcendental argument which confined itself to such properties would similarly avoid the problem of silence. But - as Strawson recognises claims of invariance are hard to establish (1966, p. 101). More plausible are various forms of a dependence claim: not that every experience must be $\mathrm{F}$, but that some experience must be $\mathrm{F}$ if there is to be any experience at all. If this is right, then although cases of silence are excluded by both formal and invariant properties, the prospects for establishing the former look more promising. ${ }^{17}$

However, this proposal offers succour to the proponent of transcendental arguments only if there is some way to identify which properties of experience are formal. And how are we supposed to do that? Kant has an answer, of course - but it is one which turns on a link between the capacity for reflection and the limitation of cognition to appearances (A268272/B324-328; CPJ 5:294). For Kant seems to suggest that reflection allows us to identify the formal properties of experience only because those formal properties are not properties of our empirical selves (de Boer, 2010, pp. 61-71; Marshall, 2014, pp. 571-572). And that requires a distinction to be drawn between appearances and thing-in-themselves. So the proposal to confine transcendental arguments in the philosophy of perception to the identification of formal properties of experience may avoid the problem of silence, but it is not obvious as yet that the proposal can be carried out without the injection of more of Kant's metaphysics than Strawson, at least, would have found amenable.

Let me summarise. I've suggested that transcendental arguments in the philosophy of perception need to find support for the conditional claim at the heart of the argument. One worry is that such support will either be empirical, in which case the contrast with the empirical method starts to disappear, or it will be analytic, in which case the argument ceases to have dialectic force. An alternative - which I suggest is the one taken in the twentieth century - is to use a process of imaginative reflection which draws on what we know about the character of our own perceptual experiences to support a conditional which claims that perceptual experience has to manifestly be a certain way if the activity in question is to be possible. This seems to capture the way in which transcendental

17 Although the features of experience which Kant identifies in the Transcendental Aesthetic look to be invariant, there are some aspects of our experience of objects which he takes to be merely formal, for instance the property of being related to the existence of other things outside me. See the discussion in the Refutation of Idealism (B274-9). 
arguments were used in a certain part of the philosophy of perception. But the use of imaginative reflection in these arguments leaves a gap which is not bridged. I've made a provisional suggestion as to how the gap might be bridged, but it remains unclear whether that proposal can be carried out without the introduction of Kantian metaphysics of the sort that some will find objectionable.

\section{Autonomy}

Where does this leave us? I've argued that transcendental arguments can be used in the philosophy of perception, but that if they are to be distinctive and persuasive, they need to make a set of additional commitments. What are the implications of this discussion for the supposed link between transcendental arguments and the autonomy of the philosophy of perception?

In discussing the prospects for transcendental arguments in the philosophy of perception, I contrasted the transcendental method with the first-person method, as practised by Moore, and the empirical method, as practised by Burge. This contrast provides one context in which to see the development of transcendental arguments, at least as they arose in British philosophy of perception in the latter part of the twentieth century. For suppose one is suspicious of the thought that the first-person perspective can reveal truths about the nature of perceptual experience - perhaps prompted by a reading of J.L. Austin's Sense and Sensibilia (1962) rather than Paul's 'Is there a Problem about Sense-Data?'. And suppose, contrastingly, that one is attracted to the Kantian idea that '[a]lthough we cannot establish anything directly about the object, we can establish some things about the nature of our sensibility... while operating purely a priori' (Harrison, 1982, p. 220). Then transcendental arguments seem to offer a way of investigating the nature of perception which is independent of both the methodological commitments of early analytic philosophy and the empirical methodologies of natural science. This is one way to understand Strawson's methodology from Individuals onwards: as allowing an a priori investigation into the nature of things which has no truck with the commitments of early analytic philosophy. ${ }^{18}$

\footnotetext{
18 Strawson comments explicitly on the methodology of philosophy in his 'Construction and Analysis', his contribution to a series of talks on the BBC Third Programme which aired in 1960 and were later published as The Revolution in Philosophy (Strawson, 1956); 'The Post-Linguistic Thaw', published anonymously in the Times Literary Supplement in 1960, and later collected in his Philosophical Papers (Strawson, 2011); and in his conversations with Ved Mehta, a New Yorker journalist who interviewed a set of 'British intellectuals' in
} 
I noted above that if the claims of necessity in a transcendental argument are supported by empirical investigation into the nature of perception, then the transcendental method looks to collapse into the empirical method. This would seem to compromise the autonomy of the philosophy of perception. One way for the transcendental method to hold on to an autonomous conception of the philosophy of perception is to take the claims of necessity in its arguments as analytic or broadly conceptual truths. For if the philosophy of perception trades in analytic or conceptual truths, its domain looks distinct from empirical work on the nature of perceptual experience. The worry, however, is that this move secures autonomy at the risk of making the arguments dialectically ineffective.

This dilemma can be avoided if we take the claims of necessity to be secured by a process of imaginative reflection. The thought here was that a defence of the main conditional in transcendental arguments might draw upon the kind of knowledge we have of the phenomenal character of our own perceptual experiences, not by taking such knowledge to directly support the conditional, but through an imaginative exploration of experiences which lack that character. If this is right, then the transcendental method has more in common with the method of early analytic philosophy than one might have supposed: for both take philosophical investigation into the nature of perceptual experience to draw upon the first-person perspective we have on our own perceptual experiences.

How does this use of the first-person perspective in the transcendental method compare to the early analytic claim that truths about the nature of perception can be revealed through our first-person perspective on perceptual experience? Answering this question requires us to be more explicit about what is involved in the process of imaginative reflection. In particular, a comparison of the transcendental and early analytic methods on this issue requires us to clarify the ways in which the first-person perspective can enter into philosophical theorising, the scope of the firstperson perspective so used, and the evidential status of claims delivered by the first-person perspective. Two methodologies which agree that the firstperson perspective plays a role in philosophical theorising may differ on these issues.

1962 (Mehta, 1962). But note that each of these concerns Strawson's understanding of the nature of philosophy at the time of Individuals, whereas the use of transcendental arguments in the philosophy of perception takes off from the discussion in The Bounds of Sense. 
Early analytic philosopher had much to say on these issues, as did experimental psychologists, and those writing in the phenomenological tradition (Spener, forthcoming). And one lesson of the foregoing is that if the transcendental method is going to secure autonomy, it too must enter into these debates. This suggests that questions about the autonomy of the philosophy of perception cannot be separated from questions about the way and extent to which the first-person perspective on perceptual experience plays a role in philosophical investigation into the nature of perceptual experience. It is on this ground that that the issue of autonomy in the philosophy of perception is likely to turn.

I'll end with a comment on our history. It is common to present analytic philosophy as born from the rejection of neo-Hegelian idealism undertaken by Moore and Russell in Cambridge at the start of the twentieth century. ${ }^{19}$ Moore's writings on the philosophy of perception play a central part of that nativity story. The transition from idealism to realism which underlies Moore's interest in the nature of perceptual experience is documented in the 1897 and 1898 dissertations which Moore submitted for the Trinity College Prize Fellowship examinations, recently published as Moore (2011). At the start of the 1897 dissertation, Moore is an idealist of the McTaggart variety. But by the end of the 1898 dissertation, he is the full-fledged realist that we know from the famous 1903 papers. Both dissertations are on Kant.

Moore's central objection to Kant, repeated in various ways across the dissertations, is that the necessary conditions which Kant sets out on various states and activities are either purely psychological conditions about the way we are conditioned to think and behave, or else purely logical truths which cannot explain the possibility of the states and activities in question. ${ }^{20}$ The charge is somewhat obscure, but in very broad terms Moore is objecting to Kant's use of something like the transcendental method on the grounds that the main conditional is either an analytic a priori truth, in which case it cannot explain the possibility of synthetic a priori knowledge, or it is an empirical truth, in which case it

\footnotetext{
${ }^{19}$ For ways in which this story obscures certain key parts of that history, see (Bell, 1999; Gomes, 2017; Kalderon \& Travis, 2013).

20 There's no straightforward passage in the dissertations which summarises this claim; it comes out clearest in the 1898 discussion, see (Moore, 2011, p. $141 \mathrm{ff}$.). The presence of the dilemma in the 1897 dissertation is made clear in Caird's examiner's report, also reprinted in the 2011 edition: see (2011, p. 103) for Caird's recognition of the issue, and the pages which follow for his [Caird's] defence of Kant on this issue. See the editors' introductory material for further discussion.
} 
concerns the psychological structure of how human beings actually operate, and cannot be used to ground claims about the nature of things.

Without evaluating the details of Moore's charge, I want to suggest that the questions I have raised about transcendental arguments in the philosophy of perception share this structure: that such arguments either rest on empirical claims about the psychology of perception, or they rest on broadly a priori conceptual truths. Moore finds both of these options wanting, in the same way that I have suggested that one might find both options wanting in the attempt to use transcendental arguments in the philosophy of perception. And though Moore doesn't move beyond the presented dilemma in these dissertations, it is not implausible to see his papers on the philosophy of perception as using the first-person perspective on perceptual experience precisely as a way of avoiding this dilemma. I've suggested that transcendental arguments, if they are to be effective, must themselves make use of the first-person perspective as a way of avoiding the dilemma. And that leaves us with the question of the extent to which we should see them as offering a radical alternative to the approach taken by Moore. ${ }^{21}$

\section{References}

Works by Kant:

References to the Critique of Pure Reason follow the standard A/B pagination and use the edition edited and translated by P. Guyer and A. Wood, Cambridge: Cambridge University Press, 1998. All other references are to the volume and page of the Akademie edition of Kant's works, Kants Gesammelte Schriften, ed. Königlich Preussische Akademie der Wissenschaften, vols. 1-29 (Berlin: de Gruyter, 1902-), with translations from the Cambridge Edition of the Works of Immanuel Kant. The titles are abbreviated as follows:

\footnotetext{
${ }^{21}$ This paper was written for a conference on Purpose and Procedure in the Philosophy of Perception that Heather Logue organised in July 2017. My thanks to all those who were present for a fantastic set of discussions and especially to my commentator, Rachael Wiseman. Later versions were presented at the University of Edinburgh and the University of Warwick; thanks to those present for questions and comments. Finally, my thanks to Colin McLear, Matthew Parrott, Andrew Stephenson, and Craig French for incredibly helpful comments and discussion on the topics of this paper.
} 
An Anthropology from a Pragmatic Point of View. In Anthropology, History and Education, R.B. Louden and G. Zöller (eds.), R.B. Louden(trans.). Cambridge: Cambridge University Press, 2007.

JL Jäsche Logic. In Lectures on Logic, J. M Young (ed./trans.). Cambridge: Cambridge University Press, 1992.

CPJ Critique of the Power of Judgment, P. Guyer (ed.), P. Guyer and E. Matthews (trans.). Cambridge: Cambridge University Press, 2002.

Works by other authors:

Allison, H. (1996). Idealism and Freedom: Essays on Kant's Theoretical and Practical Philosophy. Cambridge: Cambridge University Press.

Allison, H. (2004). Kant's Transcendental Idealism: An Interpretation and Defence (Revised and enlarged 2nd edition ed.). London: Yale University Press.

Austin, J. L. (1962). Sense and Sensibilia. Oxford: Oxford University Press.

Bell, D. (1999). The Revolution of Moore and Russell: A Very British Coup? Royal Institute of Philosophy Supplement, 44, 193-209.

Bennett, J. (1966). Kant's Analytic. Cambridge: Cambridge University Press.

Burge, T. (2005). Disjunctivism and perceptual psychology. Philosophical Topics, 33(1), 1-78.

Burge, T. (2010). Origins of Objectivity. Oxford: Oxford University Press.

Burge, T. (2011). Disjunctivism again. Philosophical Explorations, 14(1), 43-80.

Campbell, J. (2002a). Berkeley's puzzle. In T. S. Gendler \& J. Hawthorne (Eds.), Conceivability and Possibility. Oxford: Oxford University Press.

Campbell, J. (2002b). Reference and Consciousness. Oxford: Oxford University Press.

Campbell, J. (2011). Relational vs Kantian responses to Berkeley's Puzzle. In J. Roessler, H. Lerman, \& N. Eilan (Eds.), Perception, Causation, and Objectivity. Oxford: Oxford University Press.

Campbell, J., \& Cassam, Q. (2014). Berkeley's Puzzle. Oxford: Oxford University Press.

Cassam, Q. (1987). Transcendental arguments, transcendental synthesis and transcendental idealism. Philosophical Quarterly, 37(149), 355-378.

Cassam, Q. (1997). Self and world. Oxford: Oxford University Press.

Cassam, Q. (1999). Self-Directed Transcendental Arguments. In R. Stern (Ed.), Transcendental Arguments: Problems and Prospects. Oxford: Oxford University Press.

Cassam, Q. (2003). Can transcendental epistemology be naturalized? Philosophy, $78(2), 181-203$.

Cassam, Q. (2007). The Possibility of Knowledge. Oxford: Oxford University Press.

Cassam, Q. (2016). Knowledge and its Objects: Revisiting the Bounds of Sense. European Journal of Philosophy, 24(4), 907-919.

Cook Wilson, J. (1926). Statement and Inference. With other Philosophical Papers. Oxford: Clarendon Press. 
Dawes Hicks, G. (1917). Are the Materials of Sense Affections of the Mind? Proceedings of the Aristotelian Society, 17(1), 418-458.

de Boer, K. (2010). Pure Reason's Enlightenment: Transcendental Reflection in Kant's First Critique. Kant Yearbook, 2, 53-73.

Evans, G. (1980). Things without the mind-A commentary on chapter two of Strawson's Individuals. In Z. Van Straaten (Ed.), Philosophical subjects. Oxford: Oxford University Press.

Gomes, A. (2016). Unity, Objectivity, and the Passivity of Experience. European Journal of Philosophy, 24(3), 946-969.

Gomes, A. (2017). Naive Realism in Kantian Phrase. Mind, 126(502), 529-578.

Harrison, R. (1982). Transcendental Arguments and Idealism. Philosophy, 13, 211-224.

Hill, C. (2006). Modality, modal epistemology, and the metaphysics of consciousness. In S. Nichols (Ed.), The Architecture of the Imagination: New Essays on Pretense, Possibility, and Fiction. Oxford: Oxford University Press.

Husserl, E. (2002). Pure Phenomenology, its Method, and its Field of Investigation. In D. Moran \& T. Mooney (Eds.), The Phenomenology Reader (pp. 124-133). London: Routledge.

Kalderon, M. E., \& Travis, C. (2013). Oxford Realism. In M. Beaney (Ed.), The Oxford Handbook of the History of Analytic Philosophy (pp. 489-517). Oxford: Oxford University Press.

Kitcher, P. (1990). Kant's Transcendental Psychology. Oxford: Oxford University Press.

Kornblith, H. (2002). Knowledge and its Place in Nature. Oxford: Clarendon Press.

Locke, J. (1975 [1689]). An Essay Concerning Human Understanding. Oxford: Clarendon Press.

Marshall, C. (2014). Does Kant Demand Explanations for All Synthetic A Priori Claims? Journal of the History of Philosophy, 52(3), 549-576.

McDowell, J. (1986). Singular thought and the extent of 'inner space'. In J. McDowell \& P. Pettit (Eds.), Subject, Thought, and Context. Oxford: Clarendon Press.

McDowell, J. (1994). Mind and World. Cambridge, MA: Harvard University Press.

McDowell, J. (2008). The Disjunctive Conception of Experience as Material for a Transcendental Argument. In F. Macpherson \& A. Haddock (Eds.), Disjunctivism: Perception, Action, Knowledge (pp. 376-389). Oxford: Oxford University Press.

Mehta, V. (1962). Fly and the Fly-Bottle: Encounters with British Intellectuals: Columbia University Press.

Moore, G. E. (1925). A Defence of Common Sense. In J. H. Muirhead (Ed.), Contemporary British Philosophy. London: George Allen and Unwin.

Moore, G. E. (1953). Some Main Problems of Philosophy. London: George, Allen and Unwin.

Moore, G. E. (2011). GE Moore: early philosophical writings. Cambridge: Cambridge University Press. 
Paul, G. A. (1936). Is There a Problem about Sense-Data? Proceedings of the Aristotelian Society, Supplementary Volumes, 15, 61-101.

Price, H. H. (1932). Perception. London: Methuen \& Co.

Prichard, H. A. (1938). The sense-datum fallacy. Proceedings of the Aristotelian Society, Supplementary Volumes, 17, 1-18.

Quine, W. V. O. (1960). Word and Object. MIT Press.

Siewert, C. (2015). Phenomenological Approaches. In M. Matthen (Ed.), The Oxford Handbook of Philosophy of Perception Oxford: Oxford University Press.

Snowdon, P. (2007). G. E. Moore on Sense Data and Perception. In S. Nuccetelli \& G. Seay (Eds.), Themes From G. E. Moore: New Essays in Epistemology and Ethics. Oxford: Oxford University Press.

Spener, M. (forthcoming). Introspecting in the Twentieth Century. In A. Kind (Ed.), Philosophy of Mind in the Twentieth and Twenty-First Centuries. London: Routledge.

Stern, R. (Ed.) (1999). Transcendental Arguments: Problems and Prospects. Oxford: Oxford University Press.

Strawson, P. F. (1956). Construction and Analysis. In G. Ryle (Ed.), The Revolution in Philosophy. London: Macmillan.

Strawson, P. F. (1959). Individuals. London: Methuen \& Co. Ltd.

Strawson, P. F. (1966). The Bounds of Sense: An Essay on the Critique of Pure Reason. London: Methuen \& Co. Ltd.

Strawson, P. F. (2011). The Post-Linguistic Thaw. In Philosophical Writings. Oxford: Oxford University Press.

Stroud, B. (1968). Transcendental Arguments. Journal of Philosophy, 65(9), 241256.

Thomasson, A. L. (2005). First-person knowledge in phenomenology. In D. Woodruff Smith \& A. L. Thomasson (Eds.), Phenomenology and Philosophy of Mind (pp. 115-138). Oxford: Oxford University Press.

Thomasson, A. L. (2007a). Conceptual analysis in phenomenology and ordinary language philosophy. In M. Beaney (Ed.), The Analytic Turn: Analysis in Early Analytic Philosophy and Phenomenology (pp. 270). Oxford: Routledge.

Thomasson, A. L. (2007b). In What Sense Is Phenomenology Transcendental? The Southern Journal of Philosophy, 45(S1), 85-92.

Walker, R. C. S. (1978). Kant. London: Routledge \& Kegan Paul.

Westphal, K. R. (2004). Kant's Transcendental Proof of Realism. Cambridge: Cambridge University Press.

Williamson, T. (2007). The Philosophy of Philosophy. Oxford: Blackwell.

Zahavi, D. (2007). Subjectivity and the First-Person Perspective. The Southern Journal of Philosophy, 45(S1), 66-84. 